\title{
6 The rural arena
}

\author{
Stefano Borgato, Silvia Maffi \\ and Cosimo Chiffi
}

\begin{abstract}
From a transportation point of view, rural areas have always represented a challenge. Their low-density population, distance from built-up areas and railway stations, shrinking and ageing population, decentralised services are among the multiple factors that hinder the provision of adequate and efficient transport services. The scenario is even more complex when vulnerable groups not capable of moving independently are involved. Many innovative transport solutions are available, but almost all the time they stay within the urban context, outside of which they fail to reach the necessary critical mass. Given this scenario, this chapter analyses the mobility-related characteristics of rural areas before going deeper into the critical challenges related to (in)accessibility and social exclusion linked to persistent mobility poverty conditions.
\end{abstract}

\section{Introduction}

As mentioned in the introductory chapter, it is difficult to establish a single definition for the urban and this applies in the same way to the "rural". Due to a process of urban and rural restructuring, it is increasingly difficult to differentiate between urban and rural economies, societies and lifestyles. Different academic disciplines, even in social sciences, have established different concepts and definitions of rurality, some more positivistic, but increasingly approaching rurality from alternative and progressive theoretical trajectories. This conceptual plurality also means that a single and universal definition of "rural mobilities" and mobility poverty in rural areas is not straightforward. While identifying the dynamics of change in rural areas is key to making sense of contemporary processes of restructuration of the countryside, it is also necessary to analyse how people and institutions socially construct "rurality" and how concepts of rurality take effect on actual restructuring of rural landscapes (Woods 2005, 299). What we propose here is to understand and analyse rural processes and diversity in such a double 
context and not to separate them due to their different philosophical starting points. Rural space in a Lefebvrian sense is socially produced by imaginative, material and practised ruralities that form the rural as a totality (Woods 2009, 851-852; see also Halfacree 2006). Following such a perspective requires not only the analysis of mobilities in and between rural areas (and between rural and urban areas), but also investigating how mobilities, on the one hand, reshape rural places and, on the other hand, (re)produce rurality. Such an approach opens up rich pathways for a comprehensive understanding of mobility poverty in rural areas.

The rural has been, and still is to some degree, approached in academia as a functional concept, most often in its opposition to the urban and hence describing the rural-urban relationship. According to such a functional conceptualisation, rural areas are dominated by specific extensive land uses such as agriculture and forestry, are spatially structured by small and dispersed settlements and characterised by ways of living based on cohesive identities linked to land use and settlement structure (Cloke 2006, 20). Policy advice and political decision-making is still guided - to a large degree - by these functional concepts, due to the application of technology and its need for quantitative methods, but also due to the political will to respond to rural needs with policy programmes, requiring new "objective" rural classifications and sets of indicators (see e.g. Cloke 2006, 20). There needs to be a clear distinction between the political and developmental potentials of such rural concepts, and the analytical benefit for research of these concepts; as a result of that careful distinction, research needs to clearly highlight the shortcomings of policies based on such functional spatial differentiations, especially when it comes to an intrinsically fluid and multi-layered topic like mobilities and mobility poverty.

Rural areas in Europe have undergone considerable restructuring. Once densely populated spaces dominated by agriculture and other primarysector activities are today reduced in population density and marked by a variety of production activities and service economies. Rural areas have also become places of consumption: some regions that heavily rely on tourism are even overwhelmingly dominated by consumption (Halfacree 2006, Silva and Figueiredo 2013, Woods 2005, 2011). Economic restructuring and urbanisation have led to a general loss in rural population, although processes of counter-urbanisation have been described in several European countries. Structural shifts and processes of decline have been particularly dramatic in remote and peripheral rural areas (Silva and Figueiredo 2013). Most of these dynamics are related in one way or another to processes of "modernisation", such as technological innovation and organisational changes in agriculture, industries and everyday life. Many of these technological advances have enabled people to become more mobile, physically and virtually, changing people's relationship to their place of living (Woods 2005). 
Political economists and geographers have analysed the driving factors of continuous rural restructuring. They highlight how rural areas are increasingly characterised by their connections to the regional, national and global scale, making apparent that "much of what happens within rural areas is caused by factors operating outside the supposed boundaries of these areas" (Cloke 2006, 20). Such factors relate to economic globalisation that result in traditional rural agricultural products being traded on global markets that are dominated by a few transnational corporations (Woods 2005). Foreign labour migrants work as seasonal labourers in the agricultural sector and state authorities accommodate refugees in rural areas, resulting in an increasingly heterogeneous social composition of rural areas (Bell and Osti 2010, Smith 2007). All of these dynamics hint towards intensified and diversified circulation between rural and urban areas, but also between different rural areas (Hedberg and do Carmo 2012). In response to these dynamics, rural areas have been the focus of state responses such as policy reforms, land use and trade regulation, environmental protection and so on. In the face of rural deprivation, rural areas have become the recipients of tailored developmental policies on several governance levels, including the European Union (Woods 2005).

Restructuring of rural areas is hence characterised by several contradictory but parallel processes of modernisation and intensification of global-local circulation, deprivation and marginalisation as well as the re-enactment of tradition and "local values" (Murdoch 2000). This happens in spatially very differentiated and distinguished forms and these spatial differentiations are always related to various forms of mobilities and immobilities, as can be seen in several examples in European countries (see e.g., Bock, Osti, and Ventura 2016, do Carmo and Santos 2012, Rau 2012, da Silva 2012).

\section{Rural areas and their mobility characteristics}

Among the EU Member States, people living in rural areas show a certain variability in terms of their relative size. On the one hand, there are countries where the percentage of inhabitants living in rural areas is around $50 \%$ (Lithuania, Denmark, Croatia, Latvia, Hungary, Slovenia, and Luxembourg); on the other, there are several with a share under $20 \%$ (Germany, Italy, Belgium, United Kingdom and the Netherlands) (Eurostat 2017).

The total number of people living in rural areas experienced a slight increase between 2010 and 2015. However, most of the member states experienced lower population growth in rural areas than in cities and the most rapid reductions in population were registered in some of the rural and sparsely populated eastern and southernmost regions of the EU (Figure 6.1). 


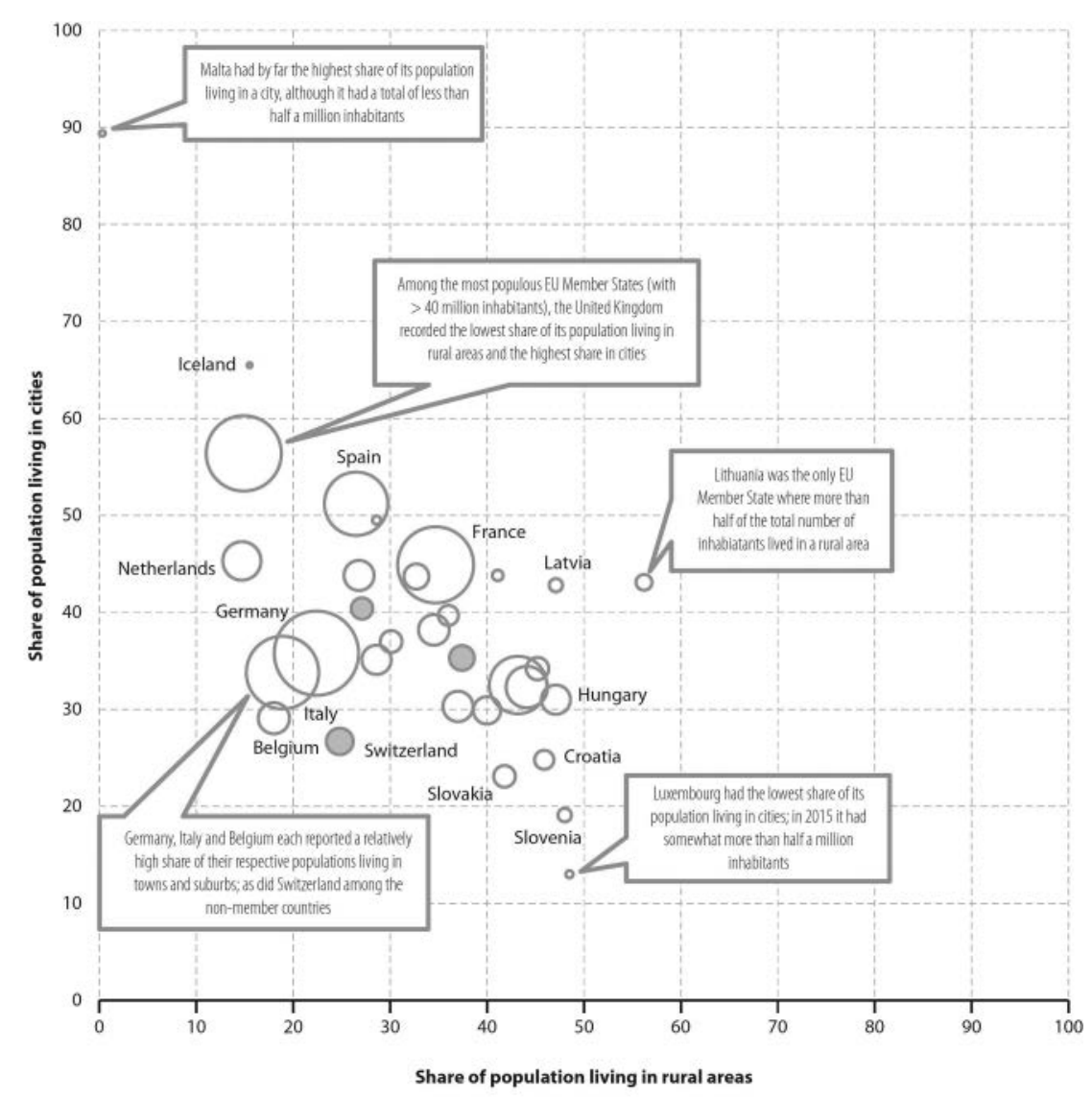

Note the area of each circle is proportional to its average population in 2015; the shaded circles denote non-

member countries (lceland, Norway, Switzerland and Serbia).

Source: Eurostat (online data codes ilic_lvhool and demo_ gind)

Figure 6.1 Distribution of the population by degree of urbanisation, 2015. Source: Eurostat 2017.

In terms of employment, around $20 \%$ of the European population is employed in rural areas, underlining the importance of such regions for the European economy (European Commission 2013b). However, $81 \%$ of rural regions still have a GDP/capita below the EU average. In addition, on average, rural areas show lower income levels and lower education levels than in urban and peri-urban areas.

Also, the elderly account for a high share of the population in rural regions. This is particularly relevant as living in rural areas as an elderly person can lead to extreme forms of mobility poverty and social exclusion, especially when transport options are inadequate and when health centres 
and other essential services are only available in cities (Manthorpe et al. 2008, Shucksmith 2003).

The European Commission identifies a series of common problems in rural areas. These include demography (exodus of residents, ageing population), remoteness (lack of infrastructure and basic services, land abandonment), education (lack of preschools and difficulty in accessing primary and secondary schools), and labour market (low employment rates, persistent long-term unemployment, high number of seasonal workers) (European Commission 2008a).

Moreover, the rural environment is often described as deprived. Deprivation usually refers to multiple domains and ranges from income and employment to health and education, from crime and security to service barriers and social involvement.

In rural areas, mobility needs are mostly satisfied by the use of private cars. On a typical day, $64 \%$ of Europeans living in rural villages use a car as compared to $38 \%$ of residents in large towns/cities (European Commission 2015). A European survey underlines the great importance of car travel for a rural population's everyday life and reveals a strong dependence on car availability due to inadequate alternative options (European Commission 2013a).

The survey also indicates some differences in car culture. Europeans who live in urban areas are more likely than those who live in rural areas to think that additional charges for the use of specific roads at specific times would be effective in improving urban travel ( $45 \%$ versus $35 \%)$. The same applies to restrictions on the use of certain types of vehicle ( $70 \%$ versus $66 \%$ ) and awareness campaigns encouraging people to limit their car use (57\% versus 53\%) (European Commission 2013a). Again, the survey reveals that Europeans in large towns are almost twice (51\%) as likely to use public transport weekly as those in small to mid-sized towns $(27 \%)$ or in rural villages $(20 \%)$ (European Commission 2013a).

Of course, these figures are subject to the different levels of available and accessible public transport. For example, in rural villages, only $65 \%$ of people live less than 10 minutes away from the nearest train station or bus stop, while in large towns this percentage rises to $87 \%$ (European Commission 2013a).

Indeed, in rural areas, $20 \%$ of respondents indicated the absence/lack of public transport coverage and $18 \%$ the infrequency of public transport connections as key problems, while the percentages in urban areas are significantly lower (European Commission 2015). Insufficient availability of public transport is one of the main reasons leading to 'forced car ownership' (FCO), i.e. households being forced to own at least one car despite limited economic resources (i.e. being materially deprived) (Figure 6.2). 


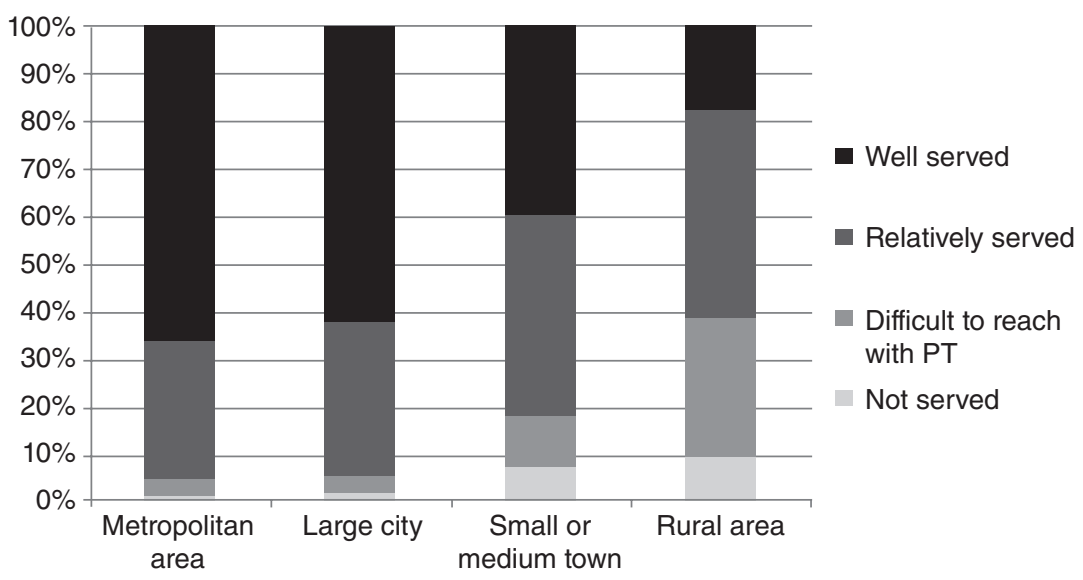

Figure 6.2 Perceived level of public transport services by level of urbanisation in the EU.

Source: European Commission 2015.

\section{Transportation and social inclusion/exclusion}

Transportation is considered as having a key role in responding to rural deprivation and rural social exclusion.

Transport policy in rural areas centres around the notion of social inclusion and is generally focused on ensuring that rural localities are inclusive of all rural citizens, including those who do not have access to private transport (Wear 2009). How to increase the mobility of all residents regardless of their socio-economic and health status, in a cost-effective way, then becomes a fundamental policy concern (Randall et al. 2018).

As regards policy advice, accessibility discourses take centre stage to inform this concern. The most critical consequence of a lack of accessibility is its contribution to social isolation for vulnerable groups. Accessibility to essential services and opportunities and access to and availability of transport options themselves are hence considered the key mechanisms for increasing the mobility of the socially and economically disadvantaged and to combat rural deprivation.

Accessibility of services is considered critical to the well-being of rural residents and the social and economic resilience of communities. Poor accessibility to services is among the factors leading to the marginalisation and peripheralisation of territories. It is argued that this may result in both a decline in economic activity and potential and low levels of socio-economic performance (low levels of well-being, quality of life, demographic ageing, economic and social stagnation) (European Network for Rural Development 2018). 
The rural transport system is then understood as either inhibiting or fostering a social and economic dynamic. It is highlighted that when access to transport in rural areas is poor and of low quality, it constrains economic and social development and contributes to poverty. On the other hand, it is emphasised that when transport access is sufficient and reliable, it is a vital factor in increasing competitiveness, sustainability and the attractiveness of rural and remote areas by ensuring the accessibility of both inhabitants and potential visitors to key services such as employment, education, healthcare and leisure activities (Cook et al. 2018).

The consequence of limited transport options is particularly relevant in remote rural regions, characterised by high dispersion and numerous small villages. Such a settlement pattern is very difficult (and expensive) to be adequately served by conventional public transport services.

People living in remote and low-density rural areas inevitably have to cope with poor and infrequent public transport services that do not allow people to retain their independence and access to basic services and facilities. Limited transport links and connections make commuting almost impracticable and accelerate the depopulation of rural areas (Samek Lodovici and Torchio 2015). As mentioned, remoteness can especially impact the quality of life of groups already at risk of social exclusion and transport disadvantaged groups, such as non-car owners, the unemployed and lowincome people, the elderly, women, migrants and young people.

Improving mobility and accessibility to services in rural areas are central policy responses to the challenges that rural regions are facing, especially remote regions, and are fundamental for breaking the circle of decline into which many rural areas are locked (Randall et al. 2018). This requires better transport infrastructures and mobility services that can reduce rural poverty by facilitating women, men and children to more readily access services (education, health, finance, markets), to obtain goods and income and to participate in social, political and community activities (Starkey et al. 2002).

\section{Car dependency and forced car ownership}

Large distances between services and population centres and the low population density make the provision of transport, especially considering an adequate frequency or service outside peak hours, very difficult and expensive. This means that people are strongly encouraged to almost exclusively rely on private transport and the use of their own car.

In many cases, in rural areas, using the private car is the principal and sole response to people's transportation needs. These experiences lead to the concept of 'forced car ownership' (FCO) (Mattioli 2017) used to define households who own at least one car despite limited economic resources (i.e., being materially deprived). It is assumed that these households potentially trade off motoring expenditure against expenditure in other essential 
areas. In households with limited resources, the enforced possession and use of a durable good can be the cause of material deprivation, economic stress and vulnerability to fuel price increases. FCO results in households cutting expenditure on other necessities and/or reducing travel activity to the bare minimum, both of which may result in social exclusion.

Beside the sustainability issues that having to exclusively rely on a private car raises, it also poses incredible challenges for the mobility of those vulnerable groups who always need to be escorted by someone else's car. Living in rural areas and being a young person, elderly or with a disability or someone who cannot independently access a car represent an extremely tough situation that can prevent access to innumerable social activities and opportunities.

In addition, it has to be considered that in rural areas around the world people are ageing. This demographic trend has a twofold effect. On the one hand, it means that there will be an increasing number of ageing drivers that will have to face the transition to becoming a non-driver. On the other, there will be an increased necessity for new kinds of services and mobility solutions to emerge. For example, fewer people will need regular public transport, whilst there will be an increasing number of people who are reliant on special transportation systems such as hospital and paratransit services (Randall et al. 2018). Alternative transport will play a key role in keeping these people engaged in mainstream society.

\section{Policy response to the vicious circle of rural mobility poverty}

While the key motivations for transport policy and mobility initiatives in urban areas are reducing congestion and pollution, the focus in rural areas is mainly on accessibility aspects, with the key question of how to increase the mobility of all residents regardless of their socio-economic and health status in a cost-effective way (Randall et al. 2018).

From a policy perspective, the rural arena is envisaged as a "vicious circle": as population density is low, the level of public transport service is generally sufficiently low to make it an unattractive alternative to the car. It is therefore not considered realistic to advance a policy goal of shifting trips from car to public transport. Hence, people in rural areas are highly dependent on cars (OECD 2009).

However, high car ownership puts pressure on existing rural public transport, prompting a diminished service, which in turn encourages even higher car ownership, creating a vicious circle of public transport decline. Also, as shown above, a transport system that is car based especially disadvantages those who are in an economically weaker position or who face a barrier due to their age or mobility impairments. These phenomena are further aggravated by processes and developments such as public budget cuts, centralisation of public services, demographic change and depopulation (Randall et al. 2018). 
The success of a rural community highly depends on access to wellplanned, efficient transport systems. Providing such systems is a complex policy, planning and governance goal because governments and administrations are struggling with different intersecting dynamics. One critical challenge is related to infrastructure as the 2017 report by the Council of Europe points out. The maintenance of road and rail networks is costly and ineffective due to the distances that need to be covered, the difficulties in integrating the two modes together and the very small number of users (and therefore revenues). In addition, the quality of transport infrastructure (e.g. existence of sidewalks, overall cleanliness and lighting) also tends to be inferior, or sometimes even non-existent, in rural areas. However, maintaining transport infrastructures and services is considered fundamental in order to keep those areas vital (Council of Europe 2017).

Hence, it can be concluded, from a transport policy point of view, that rural areas have always been a challenging place. Addressing rural transport issues is considered essential in order to reduce poverty and avoid social exclusion. Transportation access in rural areas is fundamental as it underpins the economic and employment development strategies of many local communities. On the other hand, providing services in these areas is very challenging. Conventional public transport is only a partial solution, while un-conventional services gain more attention in improving accessibility, as well as a seamless combination of appropriate transport infrastructure, improved transport services and affordable means of transport, both motorised and non-motorised.

\section{Conclusions}

Rural areas have always been a challenging place from a transportation point of view. Addressing their mobility issues is mandatory in order to reduce poverty and avoid social exclusion. Transportation access in rural areas is fundamental as it underpins the economic and employment development strategies of many local communities.

Rural transport enables workers to access employment and tourists to visit rural communities. More importantly, it allows local people to remain living in their town whilst accessing services or employment elsewhere (Wear 2009). Adequate infrastructure and access to transport give everyone the ability to travel and represent a fundamental resource in order to access employment and develop social relations in remote rural areas.

Therefore, a significant portion of a rural community's success depends on access to well-planned, efficient transport systems. Providing such systems is as urgent as it is breathtakingly complex. The difficulty starts with the word "rural" itself and most of the time it requires a seamless combination of appropriate transport infrastructure, improved transport services and affordable means of transport, both motorised and non-motorised. 
Inclusive, participative methods involving all stakeholders are essential to determine infrastructure priorities, appropriate locations for facilities and suitable means of transport. Priorities should reflect local needs, economic development and social equity goals.

Rural transport services must be actively promoted to turn the vicious circle of insufficient transport services and inability to pay for them into a virtuous circle of better transport services that stimulate economic activity and social improvement, leading in turn to easier access and more efficient transport services. This could reduce the ongoing phenomenon of the depopulation of rural areas and decrease the need for urbanisation.

Finally, it is necessary to stress the urgency to prioritise the situation of those vulnerable groups that are not capable of moving independently and autonomously. Being a young person, elderly or having a disability living in a rural area and not having the availability of suitable transportation options (aside from a private car driven by a family member) represents an extremely difficult situation. It prevents access to innumerable activities and opportunities, which consequently leads to critical social exclusion conditions. Aggravated conditions also apply to other vulnerable groups (e.g. women, those on a low income, immigrants, etc.). So, in addition to their social status' transport-related challenges, they find themselves in the situation of living in a geographically disadvantaged area from a transportation point of view.

In this sense, there are multiple inclusive mobility solutions to target vulnerable groups. However, the great majority of them are addressed to large metropolitan areas, as most of these mobility concepts require a specific infrastructure. Areas with a high population density, a mature public transportation system as well as the possibility of interconnecting different mobility options are preferred. The ultimate challenge consists in being able to successfully adapt already existing and well-established inclusive mobility solutions to serve rural needs and guarantee a brighter future for more marginalised areas as well.

\section{References}

Bell, Michael M., and Giorgio Osti. 2010. "Mobilities and ruralities: An introduction.” In Sociologia Ruralis, 50, no.3, 199-204. https://doi.org/10.1111/j.14679523.2010.00518.x.

Bock, Bettina B., Giorgio Osti, and Flaminia Ventura. 2016. "Rural migration and new patterns of exclusion and integration in Europe.” In Routledge International Handbook of Rural Studies, edited by Mark Shucksmith, David L. Brown, 101114. Abingdon: Routledge.

Cloke, Paul. 2006. "Conceptualizing rurality.” In Handbook of Rural Studies, edited by Paul Cloke, Terry Marsden, Patrick Mooney, 18-28. London: SAGE.

Cook, Japser, Cornie Huizenga, Rob Petts, Caroline Visser, and Alice You. 2018. "The contribution of rural transport to achieve the sustainable development 
goals." https://www.gov.uk/dfid-research-outputs/the-contribution-of-ruraltransport-to-the-sustainable-development-goals-factsheet. Accessed 19 March 2020.

Council of Europe. 2017. "A better future for Europe's rural areas.” Congress of Local and Regional Authorities. Council of Europe (33rd SESSION Report, CG33(2017)16final). https://rm.coe.int/a-better-future-for-europe-s-rural-areasgovernance-committee-rapporte/168074b728. Accessed 20 June 2018.

da Silva, Vanda Aparecida. 2012. "Youth "Settled" by mobility: Ethnography of a Portuguese village." In Translocal Ruralism, edited by Charlotta Hedberg and Renato Miguel Do Carmo, 73-86. Dordrecht: Springer.

do Carmo, Renato Miguel, and Sofia Santos. 2012. "Between marginalisation and urbanisation: Mobilities and social change in southern Portugal." In Translocal Ruralism, edited by Charlotta Hedberg and Renato Miguel Do Carmo, 13-33. Dordrecht: Springer.

European Commission. 2008. "Poverty and social exclusion in rural areas." European Commission DG for Employment, Social Affairs and Equal Opportunities, Unit E2. http://ec.europa.eu/social/BlobServlet?docId=2087\&langId=en. Accessed 14 June 2018.

European Commission. 2013a. "Attitudes of Europeans towards urban mobility." Special Eurobarometer 406/ Wave EB79.4. http://ec.europa.eu/commfrontoffice/ publicopinion/archives/ebs/ebs_406_en.pdf. Accessed 13 June 2018.

European Commission. 2013b. "Rural development in the EU: Statistical and economic information." European Commission - Directorate-General for Agriculture and Rural Development. http://ec.europa.eu/agriculture/statistics/ruraldevelopment/2013/full-text_en.pdf. Accessed 13 June 2018.

European Commission. 2015. "EU survey on issues related to transport and mobility." Joint Research Centre. http://publications.jrc.ec.europa.eu/repository/ bitstream/JRC96151/jrc96151_final\%20version\%202nd\%20correction.pdf. Accessed 13 June 2018.

European Network for Rural Development. 2018. "Digital and social innovation in rural services." https://enrd.ec.europa.eu/sites/enrd/files/enrd_publications/ publi-eafrd-brochure-07-en_2018-0.pdf. Accessed 19 March 2020.

Eurostat. 2017. "Statistics on rural areas in the EU - statistics explained." http:// ec.europa.eu/eurostat/statisticsexplained/index.php/Statistics_on_rural_areas_ in_the_EU\#Population_distribution_by_degree_of_urbanisation. Accessed 13 June 2018.

Halfacree, Keith. 2006. "Rural space: Constructing a three-fold architecture." In Handbook of Rural Studies, edited by Paul Cloke, Terry Marsden, Patrick Mooney, 44-62. London: Sage.

Hedberg, Charlotta, and Renato Miguel Do Carmo. 2012. "Translocal ruralism: Mobility and connectivity in European rural spaces." In Translocal Ruralism, edited by Charlotta Hedberg and Renato Miguel Do Carmo, 1-9. Dordrecht: Springer.

Manthorpe, Jill, Roger Clough, Michelle Cornes, Les Bright, and Jo Moriarty. 2008. "Elderly people's perspectives on health and well-being in rural communities in England. Findings from the evaluation of the National Service Framework for Older People." In Health \& Social Care in the Community 16, no.5, 460-468. https://doi.org/10.1111/j.1365-2524.2007.00755.x. 
Mattioli, Giulio. 2017. "Forced car ownership in the UK and Germany: Sociospatial patterns and potential economic stress impacts." In Social Inclusion, 5, no. 4, 147-160. http://dx.doi.org/10.17645/si.v5i4.1081.

Murdoch, Jonathan. 2000. "Networks-A new paradigm of rural development?." In Journal of Rural studies, 16, no.4, 407-419. https://doi.org/10.1016/S07430167(00)00022-X.

OECD. 2009. "Improving local transport and accessibility in rural areas through partnerships.” https://www.academia.edu/9935573/Improving_local_transport_ and_accessibility_in_rural_areas_through_partnerships. Accessed 19 March 2020.

Randall, Linda, Anna Berlina, Julien Grunfelder, and Arne Kempers. 2018. "Prestudy on sociocultural factors." Mamba. https://www.mambaproject.eu/wpcontent/uploads/2018/08/GoA-2.6-Sociocultural-pre-study-_Nordregio.pdf. Accessed 19 March 2020.

Rau, Henrike. 2012. "The ties that bind? Spatial (im) mobilities and the transformation of rural-urban connections." In Translocal Ruralism, edited by Charlotta Hedberg and Renato Miguel Do Carmo, 35-53. Dordrecht: Springer.

Samek Lodovici, Manuela, and Nicoletta Torchio. 2015. "Social inclusion in EU public transport." Policy Department B: Structural and Cohesion Policies European Parliament. Brussels. http://www.europarl.europa.eu/RegData/etudes/ STUD/2015/540351/IPOL_STU(2015)540351_EN.pdf. Accessed 13 June 2018.

Shucksmith, Mark. 2003. "Social exclusion in rural areas. A review of recent research." Centre for Rural Development Research. https://www.sitesplus.co.uk/ user_docs/118/File/Rural_exclusion.pdf. Accessed 19 March 2020.

Silva, Luis, and Elisabete Figueiredo. 2013. "What is shaping rural areas in Europe?" In Shaping Rural Areas in Europe. Perceptions and Outcomes on the Present and the Future, edited by Silva, Luis and Elisabete Figueiredo, 1-8. Dordrecht: Springer.

Smith, Darren. 2007. "The changing faces of rural populations: "“(re) Fixing” the gaze' or 'eyes wide shut'?." In Journal of Rural Studies, 3, no.23, 275-282. https:// doi.org/10.1016/j.jrurstud.2007.03.001.

Starkey, Paul, Simon Ellis, John Hine, and Anna Ternell. 2002. "Improving rural mobility. Options for developing motorized and nonmotorized transport in rural areas." World Bank Technical Paper No. 525. Washington DC: World Bank.

Wear, Andrew. 2009. "Improving local transport and accessibility in rural areas through partnerships." OECD LEED Forum on Partnerships and Local Governance. Handbook No.1.

Woods, Michael. 2005. Rural Geography: Processes, Responses and Experiences in Rural Restructuring. London: SAGE.

Woods, Michael. 2009. "Rural geography: Blurring boundaries and making connections." In Progress in Human Geography, 33, no. 6, 849-858. https://doi.org/ 10.1177/0309132508105001.

Woods, Michael. 2011. Rural: Key Ideas in Geography. New York: Routledge. 